\title{
CONF-970834--20
}

\section{ATOMIC RESOLUTION ELECTRON ENERGY LOSS SPECTROSCOPY OF} INTERFACES
S. J. Pennycook*, E. C. Dickey**, D.J. Wallis*, N. D. Browning ${ }^{\ddagger}$, and P. D. Nellist",
* Solid State Division, Oak Ridge National Laboratory, P.O. Box 2008, Oak Ridge, TN 37831-6030
** Department of Chemical and Materials Engineering, University of Kentucky, 177 Anderson Hall, Lexington, KY 40506-0046
\# Defence Research Agency, Malvern, UK
$¥$ Dept. Physics (M/C 273), University of Illinois at Chicago, Chicago, IL 60607
$\ddagger$ Cavendish Laboratory, Madingley Road, Cambridge, CB3 OHE,

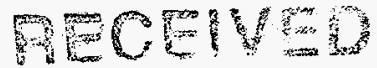
APR 221997

The ability of high resolution STEM instruments to provide EELS data at the ultimate atom C r soltion offers significant new insights into interfacial phenomena. Not only can composition profiles now be collected plane-by-plane across an interface', but in addition, the EELS near edge fine structure can be analysed to determine the valence states of atoms at the interface, and hence the nature of the bonding across the interface plane. By applying the spatial difference technique ${ }^{2}$, these effects can be studied quantitatively with high sensitivity.

Atomic resolution EELS played a critical role in explaining a completely unexpected interfacial structure found recently at $\mathrm{CdTe} / \mathrm{Si}$ interfaces grown by a particular molecular beam epitaxy growth procedure ${ }^{3}$. The high resolution Z-contrast image in Fig. 1 shows the CdTe film to be terminated by Te, but in addition, for several monolayers into the $\mathrm{Si}$ substrate, occasional columns show brighter than the surrounding $\mathrm{Si}$, although remaining in the correct position. To determine the origin of the bright columns, EELS spectra were collected plane by plane across the interface, as shown in Fig. 2. The Cd M45 edge decreased to zero by the second Si plane, whereas the Te $M_{45}$ edge continued to be detected to a depth of 4 or $5 \mathrm{Si}(200)$ layers. The Te arose from flooding the Si wafer with Te after cleaning, while still at high temperature. The temperature was then reduced significantly for growth, explaining the lack of Cd diffusion. Thus we can identify each bright spot in the image with a few (or possibly single) atoms of Te located substitutionally in that particular Si column. Careful observation of the relative positions of the Te and Si columns across the interface in Fig. 1 shows no sign whatsoever of localized interface dislocations, leading to the surprising conclusion that the interface is incommensurate. This conclusion is backed up by a maximum entropy measurement of a large $3.2 \AA$ separation between film and substrate. This spacing is too high for strong covalent bonds to form, consistent with the incommensurate interface deduced from the image. The Te detected in the substrate by EELS passivates the Si surface, allowing only a Van der Waals interaction.

The remarkable sensitivity available from spatial difference analysis is shown by a study of a $\mathrm{Ni}$ $\mathrm{ZrO}_{2}$ (cubic) interface, formed by the reduction of a $\mathrm{NiO}-\mathrm{ZrO}_{2}$ (cubic) directionally solidified eutectic ${ }^{4}$. Accurate measurement of the interplanar spacing across the interface, from maximum entropy analysis of $Z$-contrast images, indicated the interface structure to be $\mathrm{Ni}-\mathrm{ZrO}_{2}$ rather than $\mathrm{NiO}-\mathrm{ZrO}_{2}$. A more sensitive and quantitative measurement of the charge state of the $\mathrm{Ni}$ at the interface was obtained through EELS. Ni $\mathrm{L}_{2,3}$ spectra from bulk $\mathrm{NiO}$, bulk $\mathrm{Ni}$, and the $\mathrm{Ni}-\mathrm{ZrO}_{2}$ interface are shown in Fig. 4, after normalization for the contribution from the continuum. No edge is seen in the difference spectrum obtained by subtracting the metal $\mathrm{Ni}$ spectrum from the interface spectrum. A quantitative estimate of the detection limit for $\mathrm{Ni}^{2+}$ present in the interface plane is shown in Fig. 5. By mixing the (normalised) spectra for Ni metal and NiO in the proportions indicated, and subtracting the $\mathrm{Ni}$ spectrum, difference spectra could be simulated for a range of $\mathrm{Ni}^{2+}$ concentrations in the interface plane. It is clear that less that $4 \%$ of the $\mathrm{Ni}$ at the interface shows fine structure indicative of the $2+$ oxidation state.

Quantitative studies of this nature will be further enhanced when EELS becomes available on higher voltage STEMs. Although inelastic excitations are less localised than the elastic scattering used to form a Z-contrast image, for all inner shell excitations, the width of the real-space cross section is less than $1 \AA$,
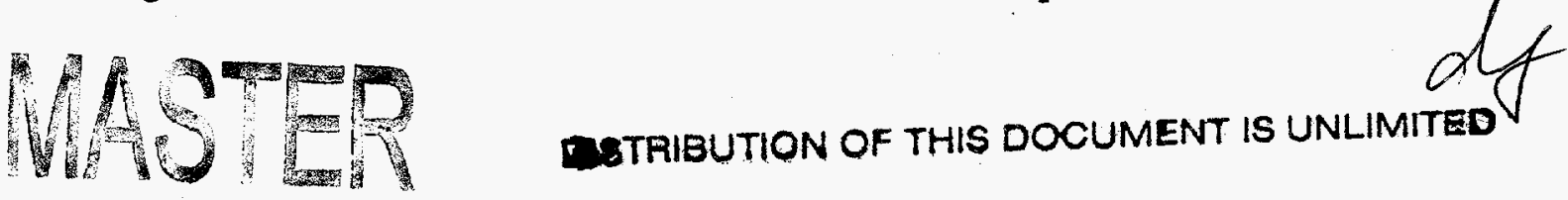


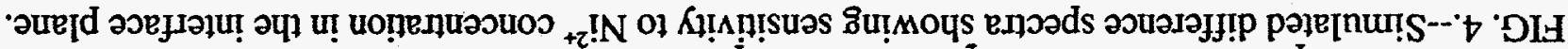

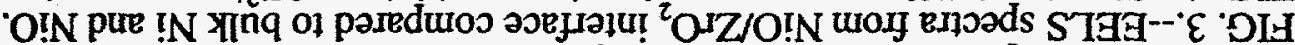

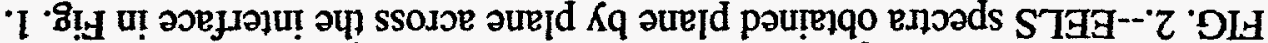

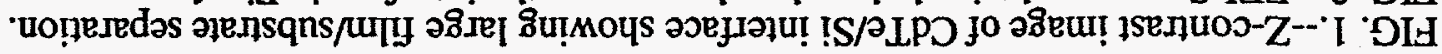

(1) $\operatorname{sson} 18 \mathrm{sarg}$

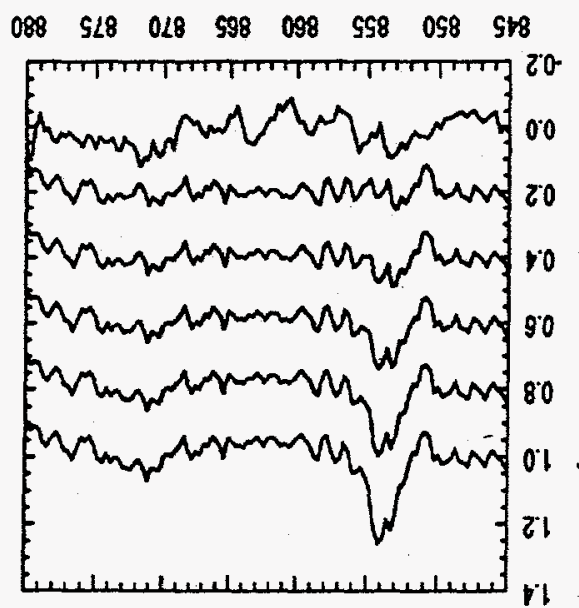

(A) $\operatorname{sson} 18124 \mathrm{~g}$

089 os cos los azs osp ot cos

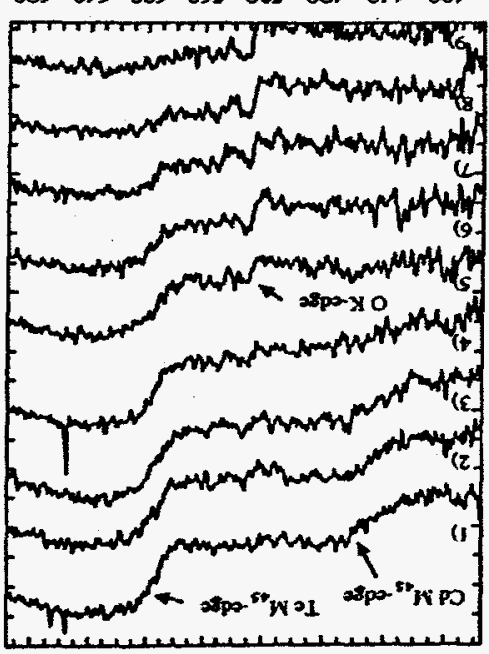

$(\Lambda$ ) 5507 hosaug

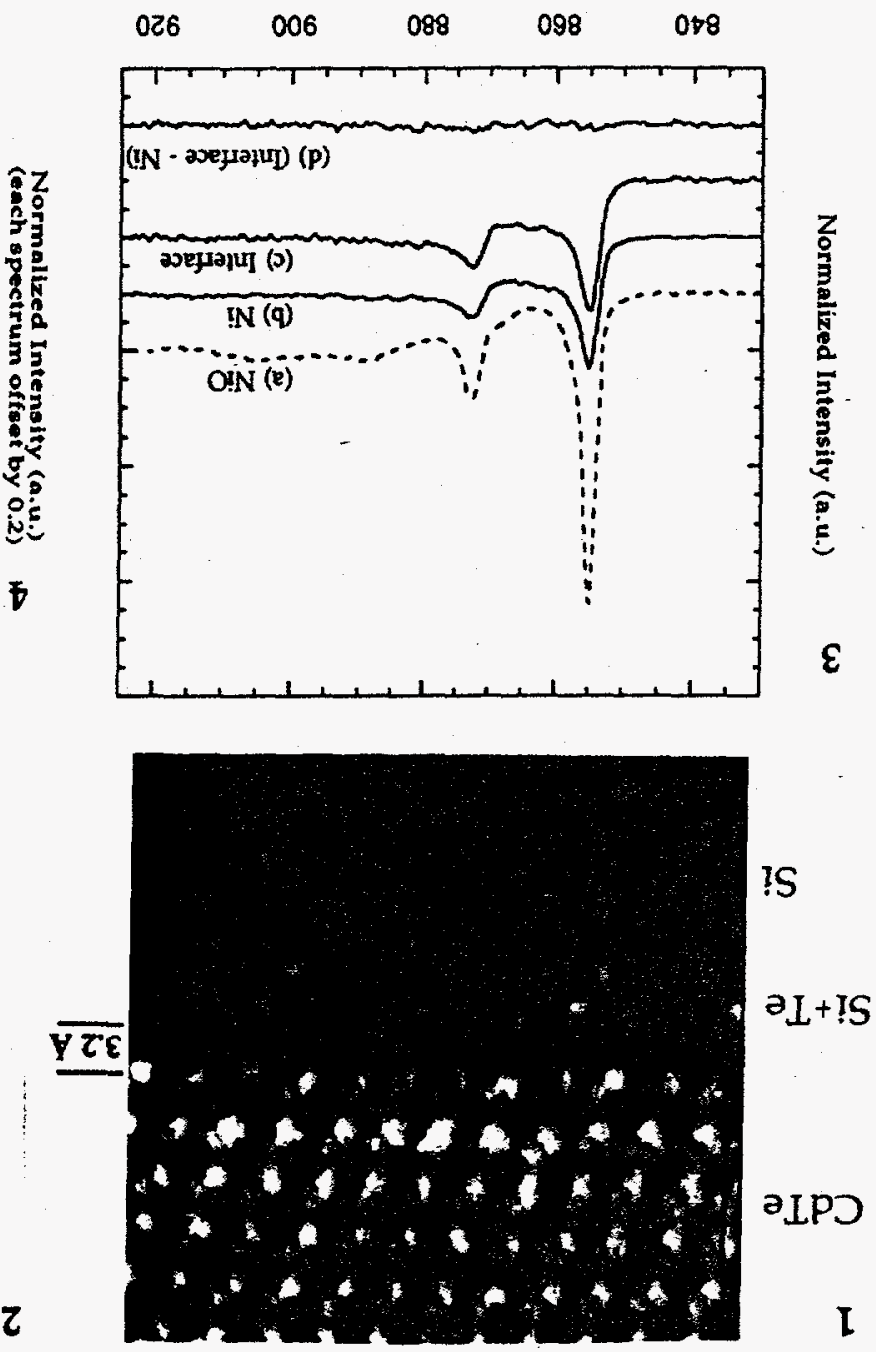

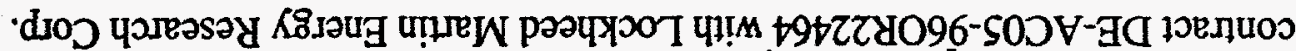

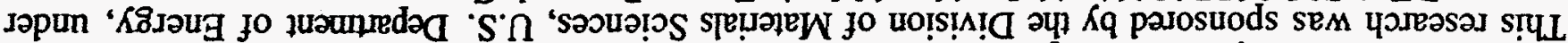

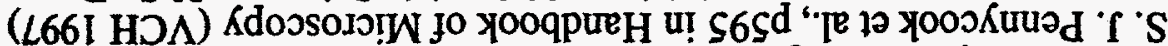

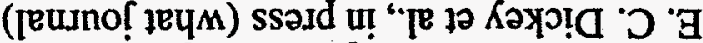
sôtparzadd วsəut "Te jo UIX ue $X$

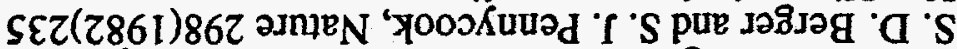

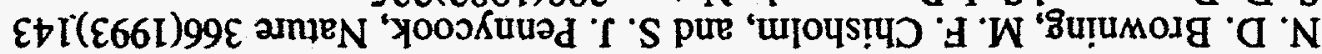

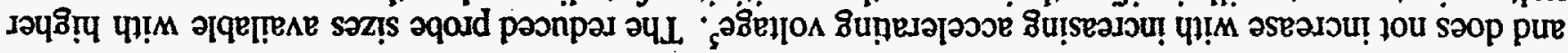




\section{DISCLAIMER}

Portions of this document may be illegible in electronic image products. Images are produced from the best available original document. 


\section{DISCLAIMER}

This report was prepared as an account of work sponsored by an agency of the United States Government. Neither the United States Government nor any agency thereof, nor any of their employees, makes any warranty, express or implied, or assumes any legal liability or responsibility for the accuracy, completeness, or usefulness of any information, apparatus, product, or process disclosed, or represents that its use would not infringe privately owned rights. Reference herein to any specific commercial product, process, or service by trade name, trademark, manufacturer, or otherwise does not necessarily constitute or imply its endorsement, recommendation, or favoring by the United States Government or any agency thereof. The views and opinions of authors expressed herein do not necessarily state or reflect those of the United States Government or any agency thereof. 